\title{
La dialéctica feminista de la ciudadanía
}

\section{Feminist Dialectic of Citizenship}

Sonia Reverter Bañón

Universitat Jaume I

reverter@fis.uji.es

\section{Resumen}

En este artículo propongo revisar el dilema de la ciudadanía que Wollstonecraft planteó en su libro Vindicación de los derechos de la mujer, de 1792. Defiendo que este dilema cae en la misma trampa en que la misma teoría feminista cayó al proponer dos modelos diferentes (y contrapuestos) de feminismo, el de la igualdad y el de la diferencia. Lo que planteo es que los dos son en realidad la misma paradoja, que remite, a su vez, al binarismo igualdad versus diferencia que opera estructurando los términos del debate liberal-patriarcal respecto a la equidad en el contrato social. El feminismo ha de salir de esa trampa para ofrecer un concepto de ciudadanía nuevo, en el que las mujeres no tengamos que decidir entre igualdad o diferencia, o entre justicia y cuidado.

Palabras clave: Ciudadanía; Igualdad; Diferencia; Contrato social

\section{Abstract}

This paper sets out to review the dilemma of citizenship Wollstonecraft raised in A Vindication of the Rights of Women, published in 1792. I argue that this dilemma falls into the same trap feminist theory does by proposing two different (and opposed) models of feminism: equality and difference. In this paper I suggest that the two are in fact the same paradox, which in turn refers to the equality-difference binarism that operates by structuring the liberal-patriarchal debate on equity in the social contract. Feminism must climb out of this trap in order to offer a new concept of citizenship in which women do not have to decide between equality and difference, or between justice and care.

Keywords: Citizenship; Equality; Difference; Social contract

\section{El dilema de Wollstonecraft ${ }^{1}$}

Cuando Mary Wollstonecraft en 1792 afirmó en su libro A Vindication of the Rights of Women "Voy a hablar en nombre de las de mi sexo" (Wollstonecraft, 1792/1796, p. 342) conectó el estatus de la ciudadanía a la identidad sexual. No fue ella, sin embargo, quien había inaugurado esta conexión. Lo que Wollstonecraft hizo al reclamar la igualdad y la plena ciudadanía para las mujeres fue hacer esa petición desde una estructura de igualdad fundamentada en la identidad de un sujeto varón como modelo de ciudadanía universal. Dos siglos más tarde, cuando la teoría feminista de la segunda ola, es decir a partir de los años 70 , desarrolla sus análisis políticos de denuncia de la desigualdad pone de manifiesto la trampa en la que se encontró Mary Wollstonecraft. Es la trampa señalada por Carole Pateman (1988/1995) como "dilema de Wollstonecraft" según el cual se fuerza a las mujeres a decidir la ciudadanía a través de una igualdad, entendida muchas veces como mismidad, (con lo cual serán "hombres de segunda"); o a través de la diferencia, entendida usualmente como diferencia respecto del modelo legitimado de sujeto, (con lo cual serán ciudadanas "de segunda") ${ }^{2}$. El desarrollo teórico del

\footnotetext{
${ }^{1}$ Agencia de patrocinio: Ministerio de Educación, Bancaixa-Universitat Jaume I

${ }^{2}$ Carole Pateman (1989, 1988/1995) denomina esta trampa "dilema de Wollstonecraft"); Joan Scott (1988) y otras teóricas feministas lo llaman "dilema de la diferencia". En los dos casos se pretende señalar la paradoja a la que se ve enfrentada la teoría feminista si no reconceptualiza el marco teórico de los conceptos de igualdad y diferencia que
} 
feminismo ha podido caer también en esta trampa, al proponer dos modelos diferentes, y en gran parte contrapuestos, de entender las políticas de emancipación para las mujeres.

Mi objetivo en este artículo es analizar el llamado por Carole Pateman "dilema de Wollstonecraft" y trazar la analogía con las diferentes vías que la teoría feminista ha planteado para la reivindicación del reconocimiento de las mujeres; es decir, fundamentalmente la vía de la diferencia y la vía de la igualdad. Mi tesis es que el problema que apunta Pateman ha llevado a la teoría feminista a encuadrar sus posicionamientos sobre la ciudadanía y sobre la diferencia sexual en el marco de un dilema donde hay que elegir entre igualdad y diferencia. Lo que pretendo argumentar es que los dos dilemas, el de Wollstonecraft y el que se interpreta que las teorías feministas han de confrontar, son uno y el mismo; el cual a su vez es una trampa que ha colapsado el conjunto de las teorías feministas atrapándolas en una falsa disyunción, que aunque ha dado fructíferos debates, es tiempo ya de abandonar para apostar por una nueva lógica que no sea dicotómica y patriarcal.

Con el dilema planteado, Pateman (1989) nos hace ver que la teoría de la democracia no ha confrontado aún las implicaciones de la construcción patriarcal de la ciudadanía, y por ello no puede proveer argumentos para solventar el complejo dilema al que se enfrentan las mujeres. Las dos vías diferentes de introducir a las mujeres en la ciudadanía dentro del orden patriarcal contemporáneo ${ }^{3}$, y dentro de los confines de las categorías presumiblemente universales de la teoría de la democracia, se concretan en:

1. Para que las mujeres sean plenas ciudadanas deben convertirse en hombres, o ser como hombres, anulando así las diferencias; o

2. Ser ciudadanas en cuanto mujeres, y entonces sus demandas no pueden verse cumplidas, pues son esas marcas de feminidad las que sitúan a las mujeres en oposición, o en una relación paradójica y contradictoria a la ciudadanía.

Por ello Pateman declara:

Las mujeres siempre han sido incorporadas al orden civil como 'mujeres', como subordinadas $\mathrm{u}$ hombres menores, y los teóricos de la democracia aún no han formulado ninguna alternativa. El dilema permanece. Lo que está claro es que si las mujeres han de ser ciudadanas como mujeres, como seres autónomos, iguales, y aún así diferentes sexualmente de los hombres, la teoría y la práctica de la democracia tiene que sufrir una transformación radical. (1989, p. 14).

El dilema de Wollstonecraft refleja las contradicciones entre los principios democráticos de la igualdad y el orden sexual de la desigualdad.

Lo que propongo es ir más allá de la disyunción que la teoría feminista a veces ha planteado entre posicionamientos desde la igualdad y posicionamientos desde la diferencia, reelaborando a su vez una

\footnotetext{
la teoría política interpretada sesgadamente (por patriarcal) ofrece.

${ }^{3}$ En la línea argumentativa que aquí defiendo el dilema se plantea precisamente en ese marco patriarcal de entender la igualdad como mismidad, y la diferencia como ocasión legítima de desigualdad. Para ello, y este es el motivo para la reconceptualización de conceptos que aquí se plantea, habremos de superar el dilema precisamente deshaciendo la trampa de esa lógica patriarcal dicotómica que está a la base de la interpretación del modelo de ciudadanía ofrecido y legitimado por gran parte de las teorías políticas modernas.
} 
dialéctica de la ciudadanía que permita superar el dilema de Wollstonecraft. Todo ello supone el desmantelamiento de la lógica dicotómica del pensamiento moderno occidental.

Desde los noventa la teoría feminista se concentra fundamentalmente en pensar un marco teórico que vaya más allá de tal dicotomía igualdad/diferencia ${ }^{4}$. Para ello se ha de deconstruir la concepción de ciudadanía moderna que sólo entiende al individuo ciudadano desde el prototipo de varón (aunque se promueva desde la universalidad). Ello nos enmarcará directamente en un planteamiento diferente de lo que se entiende por ciudadanía y por democracia.

Al hacer la deconstrucción del esquema de igualdad/diferencia borramos también la lógica dicotómica que impone el paradigma de pensar el feminismo en una u otra vía. Ello nos llevará a una nueva lógica y nuevas maneras de entender el sujeto, sin que la teoría feminista tenga que elegir, como a veces se ha podido sugerir, entre igualdad y libertad, y entre justicia y cuidado.

\section{La dialéctica igualdad/diferencia}

La dialéctica igualdad/diferencia ha estado presente en gran parte del discurso filosófico y político de Occidente. La llamada lógica de la identidad ha estado, desde Parménides, vinculada a la negación y represión de la diferencia. En el siglo XX, y siguiendo la crítica de Nietzsche a tal lógica, la filosofía occidental, de la mano de autores como Adorno, Derrida o Foucault, ha deconstruido la concepción de una razón universal cuyo cometido es clasificar, categorizar y unificar, tratando de explicar así la realidad en sustancias en vez de en procesos o relaciones. La crítica a esta lógica apunta a la ironía de la lógica de la identidad, según la cual en su intento por reducir lo que es diferente a lo mismo, convierte lo meramente diferente en lo otro absoluto (como ha señalado Iris Young en "La justicia y la política de la diferencia", 2000, pp. 168-171). Esta lógica no sólo exagera las diferencias, sino que crea dicotomías, iniciando así una distinción entre lo que está dentro de la categoría unificada de "lo universal" y lo que está fuera. Las particularidades que se "resisten" a ser unificadas serán rechazadas, y por tanto jerarquizadas en oposiciones binarias que se resumen en lo bueno/lo malo, o lo incluido/lo excluido. La unidad en la universalidad se logra sólo a expensas de rechazar o ignorar lo diferente, categorizándolo bien como diferencia irreductible o natural, o bien como diferencia accidental. La pluralidad de sujetos y diversidad de diferencias no se elimina, sino que simplemente se expulsa del ámbito de lo racional.

La lógica binaria de oposición de pares es el principio central organizador del conocimiento moderno. Es en la oposición fija de los dos términos de cualquier relación binaria que se establece una relación de interdependencia y de generación de significado. La jerarquización aplicada al binarismo completa esta lógica dual. Es ocultado, sin embargo, el hecho obvio de la interdependencia del elemento superior del par, el hombre, respecto del inferior, la mujer.

La idea de reconocimiento empleada por Georg Hegel en La fenomenología del espíritu (1966) en la dialéctica del amo y el esclavo, sin embargo, nos habla de la necesidad de interdependencia de los dos elementos binarios. Para la teoría feminista la filosofía de Hegel se ha revelado significativa precisamente porque plantea el problema de la relación entre identidad y diferencia. Como reconoce Seyla Benhabib (en su artículo "On Hegel, Women and Irony"): "[...] Hegel articula el problema fundamental de la sociedad contemporánea, con el cual las feministas están implicadas, aunque su

\footnotetext{
${ }^{4}$ En la filosofía española son especialmente interesantes las aportaciones a este respecto de Celia Amorós (1985) y de Amelia Valcárcel $(1991,1993)$.
} 
análisis se equivoca cuando 'esencializa' la diferencia sexual y todo lo que la mujer representa es confinado a la familia" (1991 p. 84). Sin embargo, y como ya señalara Simone de Beauvoir en El segundo sexo (1949/1998), si bien la categoría del "otro" en Hegel revela la reciprocidad de las conciencias y sus relaciones conflictivas en el reconocimiento, con respecto a la relación hombre-mujer no hay reciprocidad, es como la relación amo-esclavo. La mujer como el esclavo, si bien se reconoce como conciencia en la conciencia del varón, se reconoce como conciencia dependiente de aquélla; su identidad le viene concedida en cuanto se reconoce como vasalla del hombre, de lo contrario es poco femenina y traiciona su naturaleza. La mujer es la Otra absoluta, pura inmanencia que posibilita que el hombre sea pura trascendencia. No es pues, una relación recíproca, aunque en su dialéctica el ser trascendente necesite del ser inmanente, pues precisamente esta, la mujer, es la mediadora entre el hombre y las cosas, así como entre el hombre y la naturaleza.

Esa tarea de mediación que realiza la mujer posibilita conceptuar una esfera de lo civil y lo político apartada y ajena al ámbito familiar y reproductivo, que será el ámbito de las mujeres en sus tareas inmanentes. La ciudadanía reclama así, como Judith Butler nos dice "un rechazo parcial de las relaciones de parentesco que llevan a definir la existencia del ciudadano masculino" (Butler, 2001, p. 29), y que de alguna manera podemos ver en el mito de Antígona y el análisis que de él hace Hegel (1991).

Si aplicamos este análisis de la separación de las esferas de lo público y lo privado al estudio de la ciudadanía moderna aparecen varios dualismos que subyacen al concepto de ciudadanía: hombre/mujer, público/privado, trabajo/cuidado, producción/reproducción, cultura/naturaleza... Cada uno de estos pares de significados se corresponde de manera dual al primer par, al de hombre/mujer. Así, hombre se corresponde con espacio público, trabajo y producción; y mujer se corresponde con espacio privado, cuidado y reproducción. Estos significados, a su vez, organizan otros significados que de manera entretejida van conformando un espacio simbólico y cultural determinado (el patriarcado) en el que se sustenta la inferioridad de las mujeres en relación a los hombres.

El binarismo igualdad versus diferencia opera estructurando los términos del debate liberal respecto a la equidad. Un examen crítico del funcionamiento de la relación antitética de estos dos conceptos nos revela cómo la diferencia se acaba sustituyendo por desigualdad, lo cual (en carambola) acaba legitimando la desigualdad como natural, como efecto naturalizado de la diferencia. Como resultado tenemos que las diferencias son esencializadas y la desigualdad naturalizada. En esta línea la dominación aparece como una respuesta a esa diferencia y desigualdad. Y todo ello tiene sus raíces en la interpretación sesgada e interesada que el patriarcado hace del mismo ideal de universalidad de la Ilustración: podemos entender que la naturalización de la diferencia y de la desigualdad es una estrategia de la universalización, pues al permitir que la exclusión sea "natural" se traduce en que no hay colisión con el discurso universal. Caer en la lógica dicotómica tendrá como resultado caer en la esencialización de las categorías identitarias, en este caso de hombre y mujer.

La desnaturalización de la desigualdad sexual por parte de la teoría feminista ha conllevado la evidencia de lo contradictorio del discurso universal de la igualdad. Se entiende que la diferencia natural entre mujeres y hombres es la que provoca la desigualdad sexual. Sin duda es el mismo marco ilustrado el que permitirá empezar a deconstruir la naturalización de la desigualdad entre los sexos. El discurso de la igualdad se impone con fuerza a través del contractualismo moderno, que frente al medieval, inaugura el 
poder de los hermanos (de los iguales ${ }^{5}$ ) frente al poder del padre ${ }^{6}$. Los principios básicos de la llustración -libertad, igualdad, justicia- se acoplaron, en flagrante contradicción, a los del patriarcado, permitiendo así la justificación de la desigualdad entre mujeres y hombres (como lo expresa explícitamente Rousseau en sus estudios de Emile y de Sofía). Por eso el feminismo será, en palabras de Amelia Valcárcel "un hijo no querido de la llustración" (2000, p. 116) o en palabras de Celia Amorós "el test de coherencia de la llustración" (1997, p. 162).

El concepto más emblemático de la llustración fue el de razón como desenmascaramiento, y será precisamente en el tema de la igualdad, donde la razón se acabará traicionando a sí misma. Es decir, que la demanda de una igualdad apoyada en la universalidad de la razón y la naturaleza humana sale, como el conejo de la chistera, de la extensión de la naturaleza del varón a las mujeres. Con ello, aun de la mano de igualitaristas bien intencionados como John Stuart Mill o Mary Wollstonecraft, se entra de lleno en el concepto de igualdad como mismidad, o de ciudadanía como homologación (como denuncia Adriana Cavarero, 1992). En definitiva la universalización del concepto de naturaleza humana fue el hueso que la llustración no pudo roer, pero no sólo porque de facto no se universalizó, sino porque no era de sí universal al responder únicamente al sujeto varón. Es la gran contradicción performativa de la universalidad.

Hay que admitir, sin embargo, que la ideología igualitarista de la llustración permitió el marco teórico desde el cual visibilizar y contestar la dominación de las mujeres. Podemos decir que el concepto de razón universal fue la semilla que abrió la consciencia de las mujeres sobre su opresión, permitiéndoles indicar y denunciar la brecha entre teoría y práctica. Ello precisamente hace del feminismo una teoría crítica, el hecho de que actúe como crítica de la Modernidad, advirtiendo de sus propias contradicciones. En este sentido, la verdadera crítica de la Modernidad no es la Postmodernidad, puesto que no plantea alternativas, sino la teoría feminista; la cual cuestiona de manera rigurosa a la Teoría crítica de Habermas con lo que hasta ahora son sus retos e interrogantes más importantes (especialmente los presentados por Seyla Benhabib, 1992, 1995, 1996 o Nancy Fraser, 1989, 1995a).

Sabemos que la igualdad no puede renunciar a la diferencia, sino al contrario, ha de promoverla. La igualdad ha de suponer esencialmente dos derechos: el derecho a la autonomía y el derecho a la libertad; y estos derechos no pueden entenderse sin la apertura a las diferencias.

La contradicción flagrante que organiza el modelo ilustrado de una razón universal indica lo que se ha llamado "la tiranía de la falta de estructuras", como la nombró Jo Freeman (1989), que es también la tiranía de la incoherencia entre teoría y práctica ${ }^{7}$.

\footnotetext{
${ }^{5}$ Celia Amorós (1997) distingue "los iguales", los varones que entran en el pacto como tales, es decir como varones, y por tanto iguales; de "las idénticas", las mujeres, las cuales forman una amalgama homogénea como excluidas del pacto social sólo realizado a través de una individualidad que posibilita el reconocimiento como igual.

${ }^{6}$ El modelo de sociedad donde el poder es del padre es el modelo que desarrolla Filmer en El Patriarca, donde se identifica el poder político con el poder biológico de la procreación. El modelo de sociedad donde el poder público es el que se inaugura por pacto entre hermanos, es el de Locke, explicado en el Tratado sobre el gobierno civil (Cf., Amorós, 2000; Pateman, 1988/1995). El segundo sería un "pacto fraterno", en el que funcionan, como Valcárcel (1997) señala, los "iconos horizontales", dejando así el poder del padre biológico, el modelo de Filmer, en el espacio privado.

${ }^{7}$ Isaiah Berlin (1990/1992) ya señaló "la tiranía del ideal" como una de las manifestaciones culturales de Occidente. Podemos decir que es esa tiranía la que de alguna manera inicia la violencia de la Modernidad (y se relaciona con lo que J. Galtung (1990) denomina "violencia estructural"). La utopía desaforada es, como señalara también Popper, el catalizador de sociedades totalitarias y cerradas. No señalar esta tiranía y violencia, o acudir constantemente a la
} 
El efecto práctico de la lógica oposicional de la igualdad y la diferencia, o de la equivalencia de la igualdad con la mismidad, es que estructura elecciones imposibles, como la elección indicada por el dilema de Wollstonecraft. Como Luce Irigaray (1974/2007) ha señalado, esta lógica especular atrapa a la mujer, que sólo puede o incluirse en la dinámica de lo Mismo, representarse como hombre castrado e inferior, o explorar su silencio. Así, la diferencia se vuelve antitética a la igualdad, la igualdad significa mismidad (sameness), y por ello para aprehender la diferencia debemos aceptar la desigualdad. La única respuesta posible para las feministas es rechazar la dicotomía de las elecciones políticas y desenmascarar las relaciones de poder que se construyen oponiendo igualdad a diferencia, creando jerarquías binarias y promocionando la lógica de la dominación y la subordinación.

Aplicando esto a la categoría de género y al dilema de la ciudadanía planteado, entendemos que la categoría género funciona como una norma que organiza el entendimiento cultural y político de la diferencia sexual de manera dual, asignando cualidades diferentes a mujeres y hombres. Sin embargo, la alternativa a una construcción de la diferencia sexual no es la promoción de la mismidad entre hombre y mujer (una especie de androginia universal), sino la aprehensión y reconocimiento de la especificidad de las experiencias de las mujeres como individuos. Debemos ser conscientes de que el peligro es que el reconocimiento y demanda de la categoría "mujer" como posicionamiento político puede acabar también en una esencialización de la "experiencia de ser mujer", que anule otras diferencias, recreando así la cadena de exclusiones desde la legitimación de una determinada versión de lo que es ser "mujer", como algunas teóricas feministas ya han señalado.

La lógica dual que estamos analizando ha llevado a la teoría feminista a plantear las dos vías de lucha feminista dirigidas a los dos cuernos del dilema de Wollstonecraft, centrándose así en dos luchas políticas diferentes: políticas de la igualdad y políticas de la diferencia. Sin embargo, y tras décadas de debate dentro del feminismo a este respecto, opino que esta dualidad de posicionamientos políticos no ha permitido avanzar en una nueva agenda feminista que pueda aunar igualdad y diferencia. A mi juicio la teoría feminista está hoy en condiciones de avanzar en una nueva agenda de igualdad aprovechando la tarea de deconstrucción de la identidad llevada a cabo por la teoría feminista de corte postestructuralista.

Desde Sulamith Firestone (1970/1976) podemos colegir que la dialéctica del sexo es el subtexto de la dialéctica de la ciudadanía. Y ello es equivalente al análisis de Pateman según el cual el contrato social tiene como subtexto el contrato sexual. Para Pateman (1988/1995) este es en realidad el contrato originario, el pacto sexual-social, que da una forma patriarcal silenciada al pacto social ${ }^{8}$. Con él se instaura el derecho político como derecho patriarcal, iniciando la forma moderna de patriarcado. El

bondad del discurso ilustrado para salvar a los pensadores concretos que lo teorizaban pero no lo aplicaban, es parte de la violencia del "silencio lógico" de Foucault. Si la pregunta fundamental de la llustración es la del presente, como afirmó Foucault, necesario y coherente hubiera sido que el pensamiento ilustrado se hubiera preocupado de esta brecha entre teoría y realidad. Pues, como Habermas (1987) acusa a Hegel, no se puede querer la revolución de la realidad sin revolucionarios. Por eso las voces feministas vienen señalando desde hace doscientos años el fraude de la igualdad y el universalismo. El mérito no es proponer esquemas universales. Desde los griegos los tenemos ya propuestos. El mérito es que en el concepto de universal se den las condiciones teóricas para que de hecho se pueda realizar la inclusión en él de todos los seres humanos.

En este sentido me parece interesante la posición de Nancy Fraser, quien considera lo social como un campo polivalente y cuestionable, más allá de ser un espacio unidimensional bajo el dominio de la administración y la razón instrumental. Ello lleva a entender, al estilo de Gramsci, que la teoría, al identificarse con los elementos importantes de la práctica, permite acelerar sus consecuencias, y hacerla así más coherente y eficiente (ver estudio sobre Nancy Fraser en Ramón del Castillo, 1994). 
contrato social es una historia de libertad, el contrato sexual es una historia de sujeción y subordinación. Se instaura, por tanto un modelo dual de sociedad: un modelo de libertad para los varones y de subordinación para las mujeres recluidas en el espacio privado.

El pacto social patriarcal implica un pacto sexual, y ambos tendrán repercusiones en las dos esferas, pues es por medio de los dos pactos (que en realidad es uno, es un pacto sexual-social) que se instituye una dialéctica de la ciudadanía marcada por la dominación de los hombres y la subyugación de las mujeres. Con su análisis Pateman (1988/1995) enfatiza que el contrato sexual no está sólo asociado a la esfera privada. La sociedad se bifurca en dos, espacio público y privado, pero la unidad del orden social se mantiene, en gran parte a través de la estructura de las relaciones patriarcales.

En realidad la libertad de los hombres es, según este esquema interpretativo, en gran parte dominación sobre las mujeres. Como Pateman (1988/1995) argumenta, el contrato social es una idea que demuestra gran invención política, pues generando la libertad para algunos cronifica la subordinación para las mujeres, esta vez mediante un pacto civil que se suma a la "natural" desigualdad que crea la diferencia sexual. La ficción política de libertad que crea el pacto para las mujeres ha terminado incluso promoviendo dentro de la teoría feminista una manera dual de pensar el acceso de las mujeres a la ciudadanía. Sin embargo, no puede haber libertad universalizada para la ciudadanía si no se desmantela la dicotomía de las esferas privada (doméstica) y pública. Pues, como Pateman sostuvo, alguien deberá ocupar el espacio privado para asegurar la condición de libertad de la mayoría.

Una de las conclusiones de la reformulación del contrato social de Pateman (1988/1995) es llamar la atención sobre el hecho de que la diferencia sexual es en realidad una diferencia política, pues es la diferencia entre libertad y sujeción.

Afirmar esto supondrá para la teoría feminista de los años 90 problematizar la organización entera de la propia cultura y de sus relaciones con la naturaleza; es decir, reorganizar y resignificar lo simbólico. Para Sulamith Firestone (1970/1976) sólo el feminismo podrá realizar este análisis total que va de lo material y de la estructura política y económica a la comprensión de la sexualidad y los principios de configuración de la subjetividad.

Lo interesante en el contexto que aquí planteamos es la necesaria vinculación entre las estructuras económicas y materiales y las estructuras más íntimas de constitución del sujeto y de la identidad.

Los nuevos planteamientos de la teoría feminista nos dicen que, descentrado un concepto de identidad fija y estable, hay que moverse hacia la agencia, hacia la capacidad de acción del sujeto. Si la identidad es simplemente la manera que cada uno tiene de articularse en cada momento, el feminismo habrá de atender a las posibilidades, capacidades y oportunidades que las mujeres tenemos para accionar nuestros intereses. Con ello posibilitamos la dispersión de la agenda feminista en micro-luchas que permitan descentrar el mismo concepto de mujer, para no caer, como repetidamente se ha acusado, en un feminismo "blanco" que piensa en un sujeto mujer occidental. El compromiso feminista pasa finalmente por la deconstrucción de las identidades esenciales y por el análisis que teorice la

\footnotetext{
${ }^{8}$ La feminista Monique Wittig escribió originalmente en 1987 "A propósito del contrato social", donde afirmó que no vivimos bajo ese contrato ideal llamado "contrato social", sino "bajo un contrato bastardo que no dice su nombre" (Wittig, 1987/2005, p. 60). Wittig no sólo apunta a ese subtexto sexual del contrato social, sino que además argumenta que el contrato que forma parte implícitamente del contrato ideal de Rousseau es el contrato de heterosexualidad. Con ello se relaciona con el desarrollo de la llamada "heterosexualidad obligatoria" (compulsory heterosexuality) de Adrienne Rich (1980) y con el concepto posterior de Judith Butler (1990) de "ley del sexo".
} 
multiplicidad de las relaciones de subordinación. El individuo reúne un conjunto de "posiciones de sujeto" que imposibilita que se cierre su identidad en unas diferencias determinadas. La imposibilidad de hablar de un agente social unificado u homogéneo nos fuerza a aproximarnos a él/ella como una pluralidad de posiciones que coinciden en coexistencia articulándose a la manera de lo que Wittgenstein llamó "aires de familia", en propuesta interpretativa de Chantal Mouffe (1993/1999; 2000/2003).

La lógica de descentramiento del sujeto introduce la idea de un sujeto ex-céntrico (como lo llama Teresa de Lauretis, 1984/1992), un sujeto sin esencia; un sujeto que incluso necesita de-generarse. Esta degeneración plantea sin embargo la necesidad de encontrar formas productivas de pensar el mecanismo de des-identificación del sujeto con la opresión, de salirse del contrato sexual y crear un nuevo contrato social, un nuevo modelo de ciudadanía y de democracia (Cf. Cruikshank, 1999; Dhaliwali, 1996; Flax, 1992; Kymlicka \& Norman, 1994; Miyares, 2003; Phillips, 1991). Necesitamos una manera de entender la democracia como modelo participativo en el cual la ciudadanía no sólo es un estatus, sino una práctica, entendida además no sólo en el desarrollo de los derechos definidos por la tradición liberal, es decir la tríada de derechos civiles-políticos-sociales, sino aquellos que van más allá de la política formal, como los derechos reproductivos, derechos de conciliación de vida familiar y vida laboral, y derechos en general que puedan promover el bien común más allá de la visión individualista liberal, derechos que aumenten el capital social; como pre-requisito, como Robert Putnam (1993) afirmó, de una política pública efectiva y una ciudadanía saludable.

\section{Dialéctica de la ciudadanía}

El modelo de esa ciudadanía "saludable" habrá de incorporar un concepto de ciudadanía amplio, que pueda comprometerse tanto con la política formal como con la política informal. En definitiva habrá de adoptar una noción más inclusiva de lo que cuenta como ciudadanía. Ello, sin embargo, no puede llevarse a cabo sin un debate intenso y una renegociación profunda sobre un aspecto básico, que es la división por género del trabajo doméstico, del tiempo y, en definitiva de la separación de los ámbitos privado y público en roles de género. Es decir, se ha de cuestionar el estado de bienestar en su forma patriarcal con un modelo de ciudadanía restringido a un determinado concepto de participación en el que cuentan aquellos roles adjudicados a los varones y modelados sobre unas cualidades y diferencias difícilmente extensivas a otros sujetos ${ }^{9}$.

El debate sobre la ciudadanía plena se vincula estrechamente con el debate sobre las denominadas "ética de la justicia o de los derechos" y "ética del cuidado"10, tema ampliamente discutido dentro de la teoría feminista en las últimas décadas ${ }^{11}$. Sin necesidad de reproducir tal debate es necesario apuntar

\footnotetext{
${ }_{9}$ Thomas H. Marshall en su influyente trabajo sobre ciudadanía y clase social (1950/1998), aparecido originalmente en 1950, se pregunta si la ciudadanía es inconsistente con la desigualdad, concluyendo que aunque en teoría son incompatibles, en la práctica van entretejidas "tanto que la ciudadanía se ha convertido, en algunos aspectos, en la arquitectura de las desigualdades sociales legítimas" (1950/1998, p. 21-22).

${ }^{10}$ Es interesante explorar la opinión de Benhabib según la cual la ética comunicativa sí puede mediar entre el punto de vista del otro generalizado y el otro concreto al sintetizar justicia con cuidado.

${ }^{11}$ Es el debate que durante algunas décadas ha protagonizado especialmente Carol Gilligan (1982) al sostener en contra del psicólogo Lawrence Kohlberg, con quien trabajo, el diferente desarrollo moral entre niños y niñas. Las tesis de Gilligan en su libro In a different voice: psycological theory and women's development (1982) abrieron un debate que durante algunas décadas se materializó en dos interpretaciones diferentes de lo que se podría llamar una ética feminista. Bien se entendió que precisamente la ética feminista estaba contraponiendo una ética del cuidado a una ética universal de la justicia; bien se interpretaba que justamente la ética feminista pretendía
} 
que también aquí la teoría feminista necesita rehacer las propuestas de estas dos posturas para dejar claro que no pueden ser interpretadas como dicotómicas. De hecho, desde mi propuesta de superar la dicotomía del dilema de Wollstonecraft con nuevas propuestas de ciudadanía se socava también la clásica dicotomía entre ética de la justicia y ética del cuidado. A mi juicio las interpretaciones que han abogado por la distinción por una parte de un feminismo de la igualdad apoyando la ciudadanía de la homologación con el varón y la ética de la justicia; y por otra un feminismo de la diferencia defendiendo una ciudadanía diferenciada basada en una diferencia sexual quasi esencializada y reflejada en una ética del cuidado, son un ejemplo del esquema de pensamiento que sustantiviza las identidades obligándonos a un cul de sac teorético y político, probado totalmente improductivo para el feminismo.

La justicia y el cuidado no pueden verse en oposición, ni como éticas excluyentes, sino que han de conceptuarse como complementarias y en dialéctica transformadora una con otra. Es, de nuevo el sistema patriarcal organizado sobre el eje de separación de géneros el que en interés de un determinado sujeto organiza tal separación en paralelo a las esferas pública y privada. Creo que una noción de ciudadanía democrática ha de incluir, y enriquecerse, con la ética del cuidado, y ésta tiene que ser apoyada en una ética de la justicia y los derechos asociados con la ciudadanía. La separación de las dos éticas es precisamente el pilar sobre el que se ha fundamentado el modelo de ciudadanía moderno implicado en el dilema de Wollstonecraft. Tal separación de nuevo presenta aún a las mujeres de hoy en día una elección imposible entre una independencia y una autonomía entendida como alejamiento de las cargas de cuidado, de la familia y la maternidad; y una dependencia que representa la necesidad del cuidado y la imposibilidad de combinarlo con los derechos liberales de autonomía e independencia.

Con ello vemos claramente cómo el papel del ciudadano está claramente generizado. Como Nancy Fraser (1995b) nos explica el estado de bienestar ha separado los espacios de contrato y caridad respecto de la ciudadanía, siendo los primeros los que dotan verdaderamente del estatus de "ciudadano civil". Así, en un ejemplo muy ilustrativo Fraser (1995b) nos hace ver el hecho de que los derechos de seguridad del trabajador simulan la figura de un intercambio o contrato, mientras que los derechos a pensiones de viudedad no se categorizan como seguridad social, sino como "asistencia pública". Ello marca una diferencia entre derechos y ayudas asistenciales, entre ciudadanía civil y ciudadanía social (clientes de servicios asistenciales) ocultando de hecho la realidad de que todos los programas sociales, tanto los de seguridad como los llamados asistenciales, se financian mediante contribuciones.

El capitalismo de bienestar ha hinchado el papel del cliente, reduciendo el de ciudadano, a través de la burocratización de la política y la reducción de la participación a acciones formales. Pero aunque esta despolitización afecte a hombres y mujeres, Fraser enfatiza que también como clientes se da una segmentación por género, pues si bien las medidas de protección pueden reducir la dependencia de las mujeres a los hombres, acaban por desplazar esa dependencia de los hombres a la burocracia patriarcal. Perpetuándose así la dependencia y dominación de la mujer ${ }^{12}$.

De hecho, podemos decir que la no entrada plena de la mujer en la ciudadanía es la que permite mantener la separación tajante de los espacios público y privado, seña inequívoca del patriarcado y del liberalismo moderno.

reconciliar el cuidado y la justicia como la verdadera posibilidad de hablar de una ética universal. Seyla Benhabib trata en un excelente texto de interpretar una posible ética feminista como ética de superación de la dualidad justicia y cuidado (Cf. Benhabib, 1985/1990).

${ }^{12}$ El análisis que Fraser hace le permite criticar a Habermas que su esquema invisibiliza la importancia del género. 
Revalorizar y resignificar el ámbito reproductivo, así como universalizar las tareas de cuidado será uno de los elementos clave, y en gran parte aún por hacer en las sociedades democráticas. De hecho es la gran asignatura pendiente para una ciudadanía igualitaria. No cabe duda de que hay cuestiones importantes imbricadas en este debate, como son aquellas concernientes a la reproducción, a las nuevas tecnologías reproductivas, y al modelo de familia que el feminismo quiera promover. Sin entrar ahora en este debate creo que será interesante investigar desde el feminismo las nuevas formas de familia que una sociedad post-patriarcal puede acoger, como clave para seguir una agenda de des-identificación de género (Cf. Butler, 2004).

La rearticulación, no la supresión, de las esferas pública y privada es el requisito imprescindible para poder reorganizar una sociedad plenamente igualitaria; y ello debe ser atendido no sólo por la teoría feminista, sino por la teoría política, por la teoría de la democracia y por la teoría de la ciudadanía.

Lo dicho nos ha de llevar a una necesaria rearticulación en clave feminista del mismo concepto de democracia. En este sentido, dos propuestas de teoría democrática contemporánea me parecen especialmente interesantes para la teoría feminista: la propuesta de democracia agonística de Chantal Mouffe (2000/2003), y la de la teoría crítica de Seyla Benhabib $(1996,1999)$. Las dos parten de la idea de que la democracia actual supone la disolución de los marcadores de certeza y abre un periodo de indeterminación tanto en la base del poder como en la base de las relaciones del yo y del otro (en definición clásica de Claude Lefort, en Landes, 1996 p. 305).

\section{Conclusiones. Una vuelta a lo político}

Afirmar, como repetidamente ha hecho Celia Amorós, que el feminismo como lucha por la igualdad comienza con la llustración (precisamente porque es cuando el concepto de igualdad se convierte en el estandarte de la organización social) es situar la lucha feminista en la lucha por la ciudadanía. El sufragismo, más de 100 años después de la Revolución Francesa, sólo es un paso por conseguir una parte importante de la ciudadanía, que es el voto, pero el verdadero inicio no es el voto, sino la dialéctica igualdad-diferencia, que es la dialéctica de la ciudadanía ilustrada. El discurso de la Modernidad ofrece su aspecto más contradictorio cuando a la vez que instaura bases para la exclusión se ofrece como el único posible para la emancipación, manteniendo así una brecha sangrante entre teoría y práctica que supondrá su crisis más profunda.

Lo que en este artículo se propone para salir de los dilemas y paradojas que ese discurso ha impuesto a la interpretación de los conceptos de ciudadanía y de igualdad es que hay que aprender a valorar las diferencias, y ello sólo se puede hacer desde un marco de igualdad que no parta de una identidad equivalente a un concepto de individuo concreto, sino sobre la idea de la igualdad como ejercicio de consenso de diferencias en un diálogo constante. Por eso sólo podemos llegar a esa igualdad a través de un sistema democrático en el que se promueva la agencia y la palabra, el encuentro y la intersubjetividad; donde los significados estén abiertos a debate, y donde el signo político no se agote en una política determinada y cerrada. Una de las características de lo político ha de ser su apertura, sólo así se pueden trazar las luchas que permitan terminar con exclusiones históricas, como la basada en el sexo y el género.

En este "retorno de lo político", por usar terminología de Chantal Mouffe (1993/1999), la teoría feminista ha de huir de identidades sedimentadas, pues es desde ellas que se nos ha excluido y subyugado. Ello 
implica un discurso de la igualdad vinculado totalmente a la diferencia, y también al cambio, a la desestabilización identitaria, por decirlo de alguna manera. En un marco de construcción constante de lo político la inestabilidad del contenido no es peligrosa, porque hay un marco sólido que lo puede mantener: el marco de la política democrática, que es el marco de las intersubjetividades en constante apertura y renegociación, es decir la democracia. Sólo la participación, en este entramado social de continua negociación, asegura la igualdad y la libertad.

En este sentido, y como se ha argumentado a lo largo de este artículo, la controversia de los feminismos de la igualdad y la diferencia, que ha ocupado gran parte del debate feminista durante décadas, es en realidad una herencia de un discurso ilustrado de igualdad que hubo de tejer una estrategia antiuniversalista, entrando en sonora contradicción con su propio programa. El dilema de Wollstonecraft ha sido el dilema mismo del feminismo. Hay que romperlo, uno y otro. Por eso, desde el análisis que aquí propongo, creo que cuando Pateman (1992) plantea valorar la diferencia desde un sujeto maternal está cayendo en la misma trampa del dilema que ella definió: está eligiendo la diferencia esencializada frente a la igualdad.

La tesis que aquí he intentado defender es que la dialéctica de la ciudadanía es la dialéctica del feminismo. Ambos dilemas encierran la dialéctica de lo mismo y lo otro. La teoría feminista, atrapada a veces en el debate entre igualdad y diferencia, ha podido caer en la trampa de esa dialéctica falogocéntrica que se organiza en dualismos dicotómicos. La salida ha de ser una vuelta a lo político.

Entender la dialéctica de la ciudadanía, y del feminismo, pasa por entender que no hay que elegir entre una vía u otra, sino mezclar en la mediatez de las diferentes estrategias feministas las diferentes prácticas que nos acerquen a los intereses concretos ${ }^{13}$. Ahora, después de décadas de debate feminista, y desmantelado el dualismo mencionado, es cuando podemos hacer tal cosa.

El debate teórico es de suma importancia para hacer avanzar las ideas y el progreso mismo de la sociedad, y en ello la teoría feminista ha mostrado una vitalidad inusitada. La teoría feminista parte de la conciencia del potencial transformador de la teoría, aunque a su vez sabe que no es suficiente. $Y$ en ello la teoría feminista se sabe afortunada, pues aunque a veces hay más separación que la que debiera entre la academia y los grupos feministas de mujeres hay una relación mucho más fluida que la que mantiene cualquier otra teoría crítica social con la realidad, de ahí también el potencial crítico de la teoría feminista y su posible función para recuperar la razón en crisis.

Sin embargo ello no ha de hacernos caer en la trampa de que el debate ha de tener como objetivo final la elucidación de la "teoría verdadera". Ahora es momento de mantener vivo el debate en formas políticamente productivas. Pero, a su vez, es importante remarcar que ello no debe entenderse como el abandono de la utopía universalista, pues como muchas feministas vienen señalando, el feminismo no puede abandonar un ideal utópico si pretende la emancipación de los sujetos oprimidos por el sistema patriarcal (ese abandono precisamente es el que acaba convirtiendo al feminismo en apolítico).

No obstante el universalismo que la nueva agenda feminista ha de mantener no es un universalismo al uso, pues siguiendo el concepto de "mentalidad amplia" de la filósofa y feminista Seyla Benhabib (1999) se entiende que no hay valores universales, sino una moralidad universalística, según la cual es necesaria una práctica de renegociación continua que incluso ha de llevar a la habilidad para

\footnotetext{
${ }^{13}$ En cierto sentido esto es lo que propone la teoría feminista neo-pragmatista de Fraser al afirmar que "necesitamos cultivar el espíritu ecléctico" (1995a), saliendo de las falsas antítesis de la teoría feminista.
} 
distanciarse también de las creencias más profundas de una misma ${ }^{14}$. Ello está en sintonía con la concepción de un feminismo de la igualdad que, como Nancy Fraser (1989) reclama, no suponga una narrativa fundacional. La meta de tal universalismo debiera ser permanecer en "tensión creativa" con la diversidad y la diferencia, para así poder responder a las divisiones, a las desigualdades y a las exclusiones que puedan derivar de la diversidad. Es el llamado por Ruth Lister (1997) "universalismo diferenciado", y que autoras como Seyla Benhabib o Chantal Mouffe articulan en sus trabajos proponiendo desde marcos bien distintos democracias que permitan la negociación continua de lo político. A este respecto refiere también Celia Amorós cuando afirma que "la universalidad siempre es asintótica, marca una dirección, un horizonte regulativo, una tarea siempre abierta" (2000 p. 99) ${ }^{15}$.

La propuesta aquí analizada no sólo pretende superar las dicotomías de igualdad-diferencia, feminismo de la igualdad-feminismo de la diferencia, justicia-cuidado, público-privado, o incluso masculinofemenino; sino repensar la relación de la Modernidad y la crítica postmoderna más allá del dualismo clásico con el cual se ha presentado. Desde la teoría feminista ello es posible, pues más que nunca, a la luz de los desarrollos de la agenda feminista en la última década, se necesita una teorización que permita deconstruir el patriarcado a la vez que retenga la posibilidad de una narrativa universal que posibilite, a modo de utopía cercana, formas locales y particulares de contestación del dominio y la injusticia. A mi juicio ello nos habría de servir para reconstruir una razón que no esté desconectada de su contexto ni de las especificidades del sujeto, y que no caiga en la brecha entre teoría y praxis. En definitiva entiendo el trabajo de la teoría feminista del siglo XXI como un camino hacia la superación del pensamiento dicotómico, lo cual es decir hacia la superación del sistema patriarcal, y por ello creo que la teoría feminista es una teoría crítica más completa, y más cercana a una reconstrucción de la razón, que la que otras filosofías que no introducen el género pueden proponer (Campillo, 2002, 2004; Agger, 1993).

\section{Referencias}

Agger, Ben (1993). Gender, Culture and Power. Toward a Feminist Postmodern Critical Theory. Westport: Praeger.

Amorós, Celia (1985). Hacia una Crítica de la razón patriarcal. Barcelona: Anthropos.

Amorós, Celia (1997). Tiempo de feminismo. Sobre feminismo, tiempo ilustrado y postmodernidad. Madrid: Cátedra.

Amorós, Celia (Ed.) (2000). Feminismo y Filosofía. Madrid: Síntesis.

Beauvoir, Simone de (1949/1998). El Segundo sexo. Madrid: Cátedra, Universitat de València: Instituto de la Mujer.

\footnotetext{
${ }^{14}$ Para un estudio de este punto ver Sonia Reverter $(2001,2003)$.

${ }^{15}$ Creo que hay una pregunta remanente que es necesario hacerse desde el posicionamiento teórico de celebración de las diferencias por el que aquí he apostado: ¿pueden todas las diferencias considerarse iguales? Una teoría de la democracia radical y de la ciudadanía desde un punto de vista feminista habrá de incorporar una teoría del reconocimiento que nos permita defender sólo aquellas versiones de la diferencia que sean coherentemente combinadas con políticas sociales de la igualdad (el trabajo de Fraser, 1995b, en este sentido es de especial importancia).
} 
Benhabib, Seyla (1985/1990). El otro generalizado y el otro concreto: La controversia Kohlberg-Gilligan y la teoría feminista. En Seyla Benhabib y Drucilla Cornell (Eds.), Teoría feminista, teoría crítica: ensayos sobre la política de género en las sociedades del capitalismo tardío (pp. 119-150). Valencia: Alfons el Magnànim.

Benhabib, Seyla (1991). On Hegel, Women and Irony. En Mary Shanley \& Carole Pateman (Eds.), Feminist Interpretations and Political Theory (pp. 129-146). Pennsylvania: University Press.

Benhabib, Seyla (1992). Situating the Self. Gender, Community and Postmodernism in Contemporary Ethics. Cambridge: Polity Press.

Benhabib, Seyla (1995). Feminism and Postmodernism. En Seyla Benhabib; Judith Butler; Drucilla Cornell, \& Nancy Fraser (Eds.), Feminist Contentions. A Philosophical Exchange (pp. 17-34). New York: Routledge.

Benhabib, Seyla (Ed.) (1996). Democracy and Difference. Contesting the Boundaries of the Political. Princeton: University Press.

Benhabib, Seyla (1999). Sexual Difference and Collective Identities: The New Global Constellation. Signs, 24(2), 335-361.

Berlin, Isaiah (1990/1992). El fuste torcido de la humanidad: capítulos de historia de las ideas. Barcelona: Península.

Butler, Judith (1990). Gender Trouble: Feminism and the subversion of identity. New York: Routledge.

Butler, Judith (2001). El grito de Antígona. Barcelona: El Roure.

Butler, Judith (2004). Undoing Gender. New Yotk and London: Routledge.

Campillo, Neus (2002). De la identidad sexual a la identidad política. En Neus Campillo (Coord.), Género, ciudadanía y sujeto político. En torno a las políticas de igualdad (pp. 161-176). València: Institut Universitàri d'Estudis de la Dona.

Campillo, Neus (2004). Feminismo, ciudadanía y cultura crítica. Recerca. Revista de Pensament i Anàlisi, 1(4), 167-179.

Castillo, Ramón del. (1994). El feminismo pragmatista de Nancy Fraser: crítica cultural y género en el capitalismo tardío. En Celia Amorós (Coord.), Historia de la teoría feminista (pp. 258-293). Madrid: Instituto de Investigaciones Feministas Universidad Complutense de Madrid, Comunidad de Madrid.

Cavarero, Adriana (1992). Equality and sexual difference: amnesia in political thought. En Gisela Bock \& Susan James (Eds.), Beyond Equality and Difference (pp. 28-42). New York: Routledge.

Cruikshank, Barbara. (1999). The Will to Empower: Democratic Citizens and Other Subjects. Ithaca y London: Cornell University Press. 
Dhaliwali, Amarpal (1996). Can the Subaltern Vote?: Radical Democracy Discourses of Representation and Rights, and Questions of Race. En David Trend (Ed.), Radical Democracy: Identity, Citizenship and the State (pp. 42-59). New York y London: Routledge.

Firestone, Sulamith (1970/1973). La Dialéctica del Sexo. Barcelona: Editorial Kairós.

Flax, Jane (1992). Beyond Equality and Justice: Gender, Justice and Difference. En Gisela Bock \& Susan James (Eds.), Beyond Equality and Difference (pp. 193-210). New York: Routledge.

Fraser, Nancy (1989). Unruly Practices, Power, Discourse and Gender in Contemporary Social Theory. Cambridge: Polity Press.

Fraser, Nancy (1995a). False Antithesis: a Response to Judith Butler y Seyla Benhabib. En Seyla Benhabib, Judith Butler, Drucilla Cornell \& Nancy Fraser (Eds.), Feminist Contentions. A Philosophical Exchange (pp. 59-75). New York: Routledge.

Fraser, Nancy (1995b). From Redistribution to Recognition?: Dilemmas of Justice in a Post-Structuralist Age. New Left Review, 212, 68-93.

Freeman, Jo (1989). La tiranía de la falta de estructuras. Madrid: Forum de Política Feminista. Extraído el 24 julio 2009, de http://www.nodo50.org/mujeresred/feminismos-jo freeman.html.

Galtung, Johan (1990). Cultural Violence. Journal of Peace Research, 27(3), 291-305.

Gilligan, Carol (1982). In a different voice: psychological theory and women's development. Cambridge, Ma.: Harvard University press.

Habermas, Jurgen (1987). Teoría y Praxis: estudios de filosofía social. Madrid: Tecnos.

Hegel, Georg Wilhelm Friedrich (1966). Fenomenología del espíritu (Wenceslao Roces con la colaboración de Ricardo Guerra, Trad.). México, D.F.: Fondo de Cultura Económica.

Hegel, Georg Wilhelm Friedrich (1991). Estética (R. Gabás, Trad.). Barcelona: Ediciones Península.

Irigaray, Luce (1974/2007). Espéculo de la otra mujer. Madrid: Akal.

Kymlicka, Will \& Norman, Wayne (1994). The Return of the Citizen: A Survey of Recent Work on Citizenship Theory. Ethics, 104(2), 352-381.

Landes, Joan B. (1996). The Perfomance of Citizenship: Democracy, Gender and Difference in the French Revolution. En Seyla Benhabib (Ed.), Democracy and Difference. Contesting the Boundaries of the Political (pp. 295-314). Princeton: Princeton University Press.

Lauretis, Teresa (1984/1992). Alica ya no. Feminismo, Semótica, Cine. Madrid: Ediciones Càtedra. Universitat de València, Instituto de la Mujer.

Lister, Ruth (1997). Dialectics of Citizenship. Hypatia, 12(4), 6-26.

Marshall, Thomas H. (1950/1998). Ciudadanía y clase social. En Thomas H. Marshall y Tom Bottomore (Eds.), Ciudadanía y clase social (pp. 15-82). Madrid: Alianza.

Miyares, Alicia (2003). Democracia Feminista. Madrid: Cátedra-Universitat de València. 
Mouffe, Chantal (1993/1999). El retorno de lo político. Barcelona: Paidós.

Mouffe, Chantal (2000/2003). La paradoja democrática. Barcelona: Gedisa.

Pateman, Carole (1988/1995). El contrato sexual. Madrid: Anthropos.

Pateman, Carole (1989). The Disorder of Women. Cambridge: Polity Press.

Pateman, Carole (1992). Equality, Difference, Subordination: The Politics of Motherhood and Women's Citizenship. En Gisela Bock \& Susan James (Eds.), Beyond Equality and Difference (pp. 14-27). New York: Routledge.

Phillips, Anne (1991). Engendering Democracy. Cambridge: Polity Press.

Putnam, Robert D. (1993). The Prosperous Community: Social Capital and Public Life. The American Prospect, 13, 35-42.

Reverter Bañón, Sonia (2001). Feminismo y democracia: una crítica antifundamentalista. Recerca. Revista de Pensament i Anàlisi, segunda época, 1 (1), 95-108.

Reverter Bañón, Sonia (2003). La perspectiva de género en la filosofía. Feminismo/s, 1(1), 33-50.

Rich, Adrienne (1980). Compulsory Heterosexuality and Lesbian Existence. Signs: Journal of Women in Culture and Society, 5, 631-660.

Scott, Joan (1988). Deconstructing Equality-Versus-Difference: Or The Uses of Poststructuralist Theory for Feminism. Feminist Studies, 14(1), 33-50.

Valcárcel, Amelia (1991). Sexo y Filosofía. Madrid: Anthropos.

Valcárcel, Amelia (1993). Del miedo a la lgualdad. Madrid: Crítica.

Valcárcel, Amelia (1997). La política de las mujeres. Madrid: Cátedra.

Valcárcel, Amelia (2000). Las filosofías políticas en presencia del feminismo. En Celia Amorós (Ed.), Feminismo y Filosofía (pp. 115-133). Madrid: Síntesis.

Wittig, Monique (1987/2005). A propósito del contrato social. En Monique Wittig, El pensamiento heterosexual y otros ensayos (pp. 59-71). Madrid: Egales.

Wollstonecraft, Mary (1792/1796). A Vindication of the Rights of Women. London: printed for J.Johnson (tercera edición).

Young, Iris Marion (2000). La justicia y la política de la diferencia. Madrid: Cátedra, Universitat de València.

\section{Historia editorial}

Recibido: 14/07/2010

Primera revisión: 15/05/2011

Aceptado: 08/07/2011 


\section{Formato de citación}

Reverter Bañón, Sonia (2011). La dialéctica feminista de la ciudadanía. Athenea Digital, 11(3), 121-136.

Disponible en http://psicologiasocial.uab.es/athenea/index.php/atheneaDigital/article/view/758

Este texto está protegido por una licencia Creative Commons.
Usted es libre de copiar, distribuir y comunicar públicamente la obra bajo las siguientes condiciones:
Reconocimiento: Debe reconocer y citar al autor original.
No comercial. No puede utilizar esta obra para fines comerciales.
Sin obras derivadas. No se puede alterar, transformar, o generar una obra derivada a partir de esta obra.
Resumen de licencia - Texto completo de la licencia

